\title{
artículos
}

\section{Un nuevo Ecce Homo de La Roldana, y el mensaje teológico de esta iconografía en la escultura barroca española}

\author{
Fernando Llamazares Rodríguez \\ Universidad de Castilla-La Mancha
}

RESUMEN

El presente artículo estudia un nuevo busto de un Ecce Homo, propiedad del Ministerio de Justicia e Interior, que se lo ha cedido en depósito a la Cofradía de Jesús de la Redención de León, y que ofrece todas las características estilísticas y formales de la escultora barroca andaluza Luisa Roldán. A la par, se ofrece el mensaje de esta iconografía, de raigambre muy hispana, en el marco teológico.

PALABRAS CLAVE: Luisa Roldán/ Roldana/ Busto/ Barroco español/ Durero.

An unknown bust of "Ecce Homo" made Luisa Roldán "La Roldana", and the theological meaning of this iconography into Spanish baroque sculpture

ABSTRACT

This article studies a new bust of an Ecce Homo, owned by the Ministery of Justice and Interior, which has loaned it out to the Jesus' Redemption Brotherhood in León, and which offers all the formal stylistic characteristics of the Andalusian baroque sculptor Luisa Roldan. In a parallel way, the message of this iconography, of a very Hispanic tradition, is offered within the theological framework.

KEY WORDS: Luisa Roldán/ Roldana/ Bust/ Spanish baroque/ Dürer.

La cofradía de Nuestro Señor Jesús de la Redención de la ciudad de León procesiona desde 1996 un busto de madera policromada del "Ecce Homo", propiedad del Ministerio de Justicia e Interior, que se lo ha cedido en depósito para su exposición y desfile procesional ${ }^{1}$. Desde el primer momento nos llamó la atención la alta calidad de esta obra, de tal modo que la calificamos como una estupenda manifestación barroca de Cristo, incluyéndola dentro de los esquemas de "Ecce Homo" que tanto predicamento había tenido durante el barroco español, popularizados entre otros artistas por Pedro de Mena ${ }^{2}$. Después de detenidos análisis estilísticos y for-

\footnotetext{
* LLAMAZARES RodrígueZ, Fernando: "Un nuevo Ecce Homo de La Roldana, y el mensaje teológico de esta iconografía en la escultura barroca española", en Boletín de Arte, $n^{\circ} 30-31$, Departamento de Historia del Arte, Universidad de Málaga, 2009-2010, págs. 87-95. Fecha de recepción: Marzo 2009.

${ }^{1}$ Esta escultura antes de de su llegada a León se encontraba en un estado un tanto deplorable, de tal modo que se hizo totalmente necesaria una pertinente restauración con cargo a la cofradía, pues mostraba pérdidas de volúmenes en varias zonas. Había piezas desencajadas y sueltas. Dos clavos amarraban el antebrazo con el brazo. Una corona de espinas presentaba elementos alámbricos, desperfectos en la policromía etc. Sin afectar para nada a la estructura original, esta imagen es revestida con una túnica desde la cintura hasta los pies y un manto de de tela sobre sus espaldas, imitando de este modo figura de cuerpo entero para así presentarla con la máxima dignidad en los desfiles procesionales semasanteros. Quiero dejar aquí constancia de mi más profundo agradecimiento a la Cofradía de Nuestro Señor Jesús de la Redención de León por las facilidades y atenciones que me prestaron para estudiar este obra

2 LLAMAZARES RODRÍGUEZ, Fernando: “La escultura procesional en León”, Semana Santa en León, León, 2000, pág. 99.
} 
males creemos no solo que este busto corresponde a la escultora sevillana Luisa Ignacia Roldán (1652-1706), más conocida como La Roldana, sino que además es una manifestación muy sobresaliente en el conjunto de su producción artística. Consideramos esta obra de la etapa de madurez de la escultora y perteneciente a su período madrileño ${ }^{3}$.

Este Ecce Homo, de tipo de busto cortado horizontalmente a la altura media de las nalgas, de 94 centímetros de altura, está tomado puntualmente del grabado del mismo tema de cuerpo entero firmado por Alberto Durero en 1512, si bien invirtiendo la posición. El simulacro de Jesús muestra su pecho semidesnudo, pues está cubierto en parte por una clámide que a la par tapa su espalda, y deja sus brazos caídos y cruzados por delante de la cintura con ademán de estar maniatado. Su cabeza, inclinada hacia su derecha, con cabellera abundante y distribuida simétricamente sobre sus hombros, ofrece un rostro de dolor contenido, con mirada baja, boca entreabierta cargada de ansiedad, y barba que finaliza en una perilla partida bilateralmente. Provisto de los habituales postizos - ojos de cristal, pestañas y dientes de pasta - se completa con una cuidada policromía brillante en las encarnaciones de su torso, rostro, brazos y manos destacando con un color azulado el recorrido de sus venas. Las heridas propiciadas por la coronación de espinas y muñecas maniatadas se traducen en chorretones de sangre. Cabellos y barba se pintan en color negro, mientras la clámide toma un tono rojizo con una fina cenefa de roleos dorados.

Formalmente este busto se vincula íntimamente con los dos autógrafos de Luisa Roldán de la catedral de Cádiz e iglesia de San Francisco de Córdoba 4 . El esquema compositivo de los tres tiene como fuente común el grabado, ya citado, de Durero, si bien el que más se ciñe a él es el que ahora nos ocupa. Esta tríada presenta en común una concepción poderosa en la anatomía de tronco, brazos y manos, aflorando venas y tendones con gran sensibilidad en su epidermis, además se repite en los tres toda una serie de sintagmas estilísticos propios de su autora en la distribución de cabellos y perilla, configuración de ojos, cejas, boca y nariz, pero donde la coincidencia ya es total es en la elaboración de brazos, manos y dedos por los que discurre la misma disposición de nervios y venas. El grosor en las falanges proximales de las manos hasta su unión con las medias queda destacado notablemente y se vuelve también a ampliar en las distales, característica esta repetida en gran parte de su producción 5 .

\footnotetext{
3 Sobre la bibliografía existente de Luisa Ignacia Roldán puede consultarse el muy completo repertorio recogido en Cat. Exp. Roldana, Sevilla, 2007, págs. 227-235.

4 El busto gaditano fue completado con el resto del cuerpo, posteriormente, de tal modo que ha quedado convertido en escultura total de bulto entero. Véase: HORMIGO SÁNCHEZ, Enrique: "Historia de una escultura. El Ecce Homo de la Catedral" Diario de Cádiz, 29-3-1985. Sobre esta obra puede consultarse también, PLEGUEZUELO HERNÁNDEZ, Alfonso: "Una obra de Luisa Roldán. El Ecce Homo de la Catedral de Cádiz", Diario $A B C$, Sevilla, 14-12, 1984. En el interior de este Ecce Homo, hay un documento explicativo que entre otros datos afirma que había sido realizado por "La insigne artífice doña Luisa Roldan en compañía de su esposo Luis Antonio de los Arcos".

5 En el momento de la restauración se le añadió algún dedo como el pulgar de la mano derecha pues ya faltaba.
} 
1. LUISA IGNACIA ROLDÁN. Ecce Homo. Vista frontal.

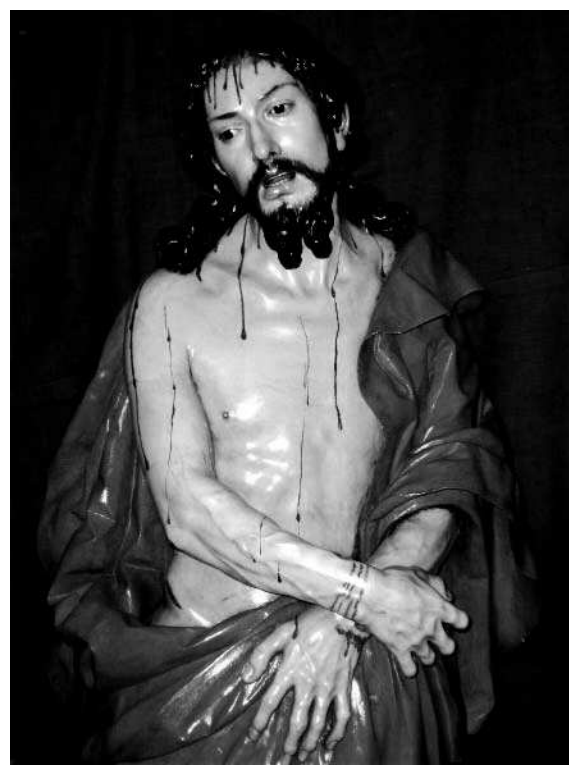

No obstante, también hay sustantivas diferencias entre ellos, pues los dos ejemplares andaluces, anteriores en el tiempo, ofrecen un rostro más dramático y tanto las voluminosas coronas de espinas que se tallan sobre sus cabezas, como el protagonismo que toman las sogas que se unen y anudan los extremos de las clámides a la altura de uno de los hombros, como las que cuelgan del cuello hasta maniatar con seguridad al Reo, son elementos pasionistas muy reales y convincentes inherentes al momento escenificado. Esa esencialidad plástica quedará muy atemperada en el modelo que nos ocupa, pues aquí, si bien no se suprimen aquellos instrumentos de horror pues así lo exige la iconografía, se sustituirán por añadidos postizos, con un carácter más naturalista. En los tres modelos se añade una caña natural que portan en su mano izquierda.

Pero, si la relación formal con sus homónimos gaditano y cordobés es clara, hay que tener muy presente además la profunda vinculación, en fondo y forma, con el rostro del Nazareno del convento conquense de Clarisas de Sisante ${ }^{6}$. El modelado del rostro de ambos es muy semejante y más delicado y dulce que en el caso de los dos anteriores, mucho más dramáticos. Bien se puede comprender aquí que una y otra obra deberán de estar muy cercanas en el tiempo. En ambas imágenes la concepción de las cabezas, ligeramente caídas y ladeadas hacia su derecha por el can-

6 Sobre el Nazareno de Sisante véase principalmente: PLEGUEZUELO HERNÁNDEZ, Alfonso: “Jesús Nazareno de Sisante. Una imagen con Historia”, Padre Jesús de Sisante, n 4, Cuenca, 2008, págs. 17-28. 


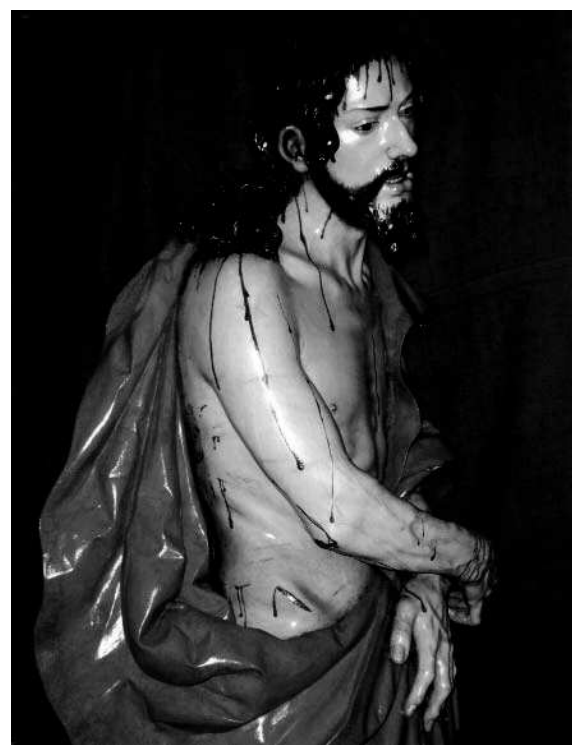

2. LUISA IGNACIA ROLDÁN. Ecce Homo. Vista de perfil.

sancio, es muy semejante, y en una y otra se disponen tres huecos para la colocación de potencias que en el caso del conquense las lleva colocadas. El tratamiento suavísimo de sus rostros, la configuración de los ojos con la mirada baja, la delicadeza del ceño, las cejas alargadas, el mismo tipo de nariz muy correcta, las bocas entreabiertas en un suspiro agotador, permitiéndonos ver dentadura y lengua, la descripción capilar no excesivamente abundante de barba y bigote y la misma disposición de perilla proclaman en todo ello una idéntica gubia. En cuanto al tratamiento de la clámide que cubre parte de su pecho y espalda, ofrece una abultada tela rojiza con cenefa dorada con roleos, de aspecto duro, que se quiebra en dobladuras de efectos casi metálicos y claroscuristas que se vincula también estilística y formalmente también con su última etapa y más concretamente con el tratamiento de paños de obras como la de la escultura de San Miguel de el Monasterio del Escorial.

Esta tipología de imágenes de busto, tanto de Cristo sufriente como de la Virgen Dolorosa, por lo común destinados a espacios apartados y solitarios en centros conventuales y oratorios particulares, sería el mejor nexo para la oración mental y meditación espiritual individual del más puro espíritu intimista. A este respecto bueno es tener en cuenta, para mejor centrar la obra que nos ocupa, como entre los años 1702 y 1705 se conserva una carpeta de cuentas con pagos a Luisa Ignacia Roldán pertenecientes a la casa del duque del Infantado, entre cuyas esculturas documentadas se halla un Ecce Homo, una Virgen sedente dando el pecho al Niño y un gran Nacimiento con destino al convento del Rosal en la localidad conquense de Priego que estaba bajo el patronazgo del Infantado, cuyas obras no han podido ser identifi- 
cadas ${ }^{7}$. Por las fechas tan tardías de estas cuentas, ese Ecce Homo documentado de La Roldana muy bien podría tratarse del ejemplar que ahora estudiamos ${ }^{8}$.

Sin lugar a dudas, estas manifestaciones pasionistas son claramente devocionales y muy del gusto del Barroco. La literatura acética y mística del Siglo de Oro es pródiga en la contemplación de la Via Dolorosa, y muchos de sus textos subyacen bajo las formas artísticas. Pero, en esta tipología de "pasos" de Ecce Homo, se hace voluntariamente abstracción de cuantos personajes componían el pasaje evangélico. Todo y todos cuantos rodeaban aquel escabroso acontecimiento sobra. Se ha preferido dejar al protagonista en su soledad". El "Ecce Homo", ese Hombre solo, en este preciso instante, únicamente entrará en diálogo íntimo con el alma cristiana preparada espiritualmente que a Él se acerca, también apartada de todo y de todos. Pero es necesario, para una más exacta comprensión de este pasaje cristológico, contextualizarlo en su mensaje teológico.

\section{El mensaje teológico y su plasmación En La ESCULtura.}

Por antonomasia hay dos expresiones bíblicas neotestamentales que, por su alto contenido cristológico, se ofrecen sin traducción: "Ecce Homo" e "INRI", y ambos conceptos están indisolublemente unidos entre sí en el proceso y crucifixión de Jesús, teniendo como responsable clave de los mismas la persona del procurador romano Poncio Pilato. Él planteó a Jesús la peligrosa acusación de ser el "rey de los judíos", cuya pregunta se la formuló antes de exhibirlo al pueblo "Ecce Homo": "Entonces Pilato entró de nuevo al pretorio y llamó a Jesús y le dijo: ¿eres tú el rey de los judíos? (Jn 18, 33). Esa expresión "rey de los judíos" sería confirmada, a continuación, por el título de la cruz "INRP".

Estas dos proclamaciones están recogidas en el Evangelio de San Juan. La afirmación "Ecce Homo" responde al capítulo 19, 5: "Salió entonces Jesús fuera llevando la corona de espinas y el manto de púrpura". Díceles Pilato: "Aquí tenéis al hombre". Las siglas "INRP" están tomadas del capítulo 19, 19-22, que dice: Pilato redactó también una inscripción y la puso sobre la cruz. Lo escrito era: "Jesús el Nazareno, el Rey de los Judíos". Esta inscripción la leyeron muchos judíos, porque el lugar donde había sido crucificado estaba cerca de la ciudad; y estaba escrita en hebreo, latín y griego. Los sumos sacerdotes de los judíos dijeron a Pilato: "No escribas: el Rey de los judíos, sino: "Éste ha dicho: Yo soy Rey de los judíos". Pilato res-

7 HALL VAN DEN ELSEN, Catherine: "Luisa Roldán, La Roldana: aportaciones documentales y artísticas", Cat. Exp. Roldana, op. cit., pág. 26

8 El convento de Nuestra Señora del Rosal que hubiera pertenecido a la Orden Concepcionista hoy día es una gran ruina. Con toda probabilidad esas obras citadas serían desamortizadas.

9 Esa soledad voluntaria y dolorosa aquí contemplada, está recogida en "Las despedidas", tras la Última Cena, cuando Jesús dijo a sus amigos, "a donde yo voy no podéis ir vosotros" (Jn, 13, 33). A la par la soledad y el silencio serán inherentes también al movimiento religioso de la Devotio moderna. 


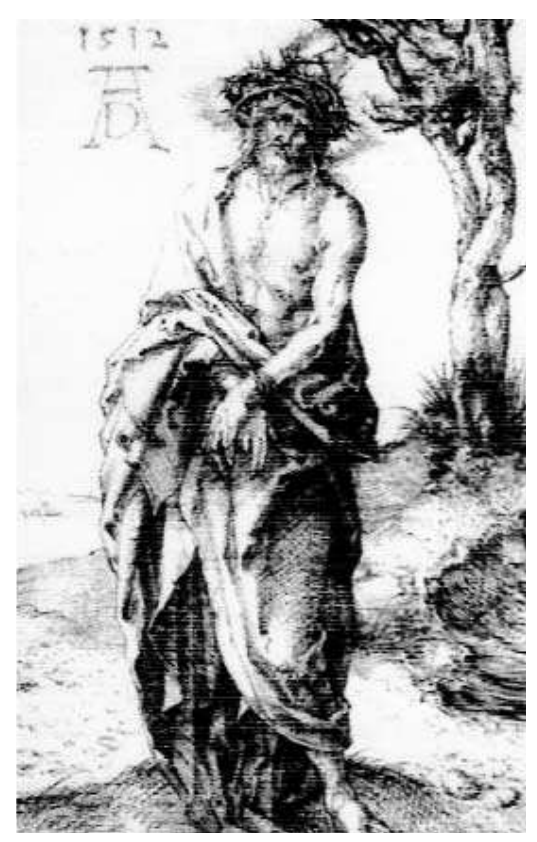

3. Alberto DURERo. Ecce Homo, 1512. Calcografía a punta seca.

pondió: "lo que he escrito, lo he escrito".

La acusación contra Jesús como rey de los judíos era la que más le importaba a Pilato, por cuanto pudiera afectar a rebelión o levantamiento político por eso le formuló esa pregunta, esperando que le respondiera que anunciaba un reino distinto del que él representaba y cuyo orden él debía de mantener: Pilato le preguntaba: “¿Eres tú el Rey de los judíos?” Él le respondió: Sí tú lo dices. Los sumos sacerdotes le acusaban de muchas cosas. Pilato volvió a preguntarle: “¿No contestas nada? Mira de cuántas cosas te acusan". Pero Jesús no respondió ya nada, de suerte que Pilato estaba sorprendido"10. Aquí subyacen las palabras del profeta: "Fue oprimido, y él se humilló, y no abrió la boca. Como un cordero al degüello, y como oveja que ante los que la trasquilan está muda, tampoco él abrió la boca" (Is, 53, 7).

Tras el azotamiento, coronación de espinas, vestirlo con manto color púrpura, abofetearlo y ridiculizarlo con el saludo "salve rey de lo judíos" a continuación Pilato no encontrando delito en Él, le presentó al pueblo, coronado de espinas y con el manto purpúreo, como el Hombre. "Ecce Homo", "idoú ò Ánthropos". Aquí, se manifiesta la conciencia de Jesús de ser el Hijo de Dios (Jn 19,7) y, en contraposición a los hombres que deberían de reconocerlo como Hijo de Dios, es presentado como el Hombre humillado y escarnecido. El hombre presentado por Pilato es para los lecto-

10 Sobre el concepto de rey de los judíos puede consultarse: FERNÁNDEZ RAMOS: Felipe, Pasión de Nuestro Señor Jesucristo, Salamanca, 2007, págs. 156-159. 
res del evangelio su Señor y su Dios ${ }^{11}$. Según C. K, Barret, en su Comentario al cuarto evangelio, al hacer Pilato esta presentación no pensaba en nada de eso. Sus palabras, más allá de la piltrafa humana que tenía delante y que se presentaba con unas pretensiones demenciales, tienen una carga teológica conferida por el evangelista cuya intención va mucho más allá de la materialidad lingüística utilizada para expresarla12.

Autores como B. Lindars ven en el pasaje joánico del "Ecce Homo" una velada alusión al "Hijo del Hombre" y C. K. Barret, afirma que el texto que mejor reflejaría el sentido original de la expresión del "Hijo del Hombre" nos la ofrece el cuarto evangelio en el texto 19, 5: "idoú o Ánthropos", en la misma línea que el autor anterior, el conocido como "Ecce Homo" con cuya indicación Jesús había sido presentado al pueblo por Pilato. Otra interpretación relativamente reciente lo presenta como un título cristológico que es reconocimiento de su dignidad real y divina: el hombre Jesús, en su debilidad e impotencia, posee el poder de juez de la Historia, como "Hijo del Hombre". En el Hombre se halla subyacente, al menos con gran probabilidad, el mito judío o helenista del hombre celeste, del hombre primigenio que parece estar vinculado a la expresión "el Hijo del Hombre". El cuarto evangelio empalma con el pensamiento apocalíptico del hijo del hombre, que consideraba esta figura como un ser celeste que, al bajar el último día, establecería el contacto con el cielo y la tierra13.

Este pasaje del "Ecce Homo" tiene también una clara concordancia con el del testimonio de Juan el Bautista cuando al ver a Jesús exclamó: "Ecce Agnus Del" (Jn 1, 29, 36). Si bien ambas expresiones se desenvuelven en situaciones muy distintas, sin embargo resultan complementarias, pues Jesús, el Cordero de Dios, es además el Hombre perfecto, el paradigma humano que Dios muestra al mundo, aquel que entrega su vida por los demás, su revelación definitiva.

Esa idea de hombre perfecto, en el "paso" de Jesús como "Ecce Homo", se ha trasmitido fielmente en la materialización de los rasgos formales en la escultura barroca española, pues a pesar de tanta tortura previa que le habría convertido en una piltrafa humana, se nos ofrece no solo la grandeza sicológica de la persona sino una anatomía, por lo general, elegantemente elaborada en todos sus miembros. Bajo estas cuidadísimas imágenes del "Ecce Homo" subyace la imagen de belleza exaltada en el salmo 45 (44), 3: "Speciossus forma prae filiis hominum, difusa est gratia in labiis tuis, propterea benedixit te Deus in aeternum et in saeculum saeculi".

Un concepto de idealización formal clásico se manifiesta con claridad en la amplísima nómina de bustos de este género que abundaron en el Barroco español, principalmente en el foco castellano y más singularmente en el andaluz. Pero ya en Castilla, en el siglo XVI, existía un claro precedente en este sentido creado por Juan

\footnotetext{
11 FERNÁNDEZ RAMOS, Felipe: “Ecce Homo”, Diccionario del mundo joánico, Burgos, 2004, pág. 270.

12 Recogido por FERNÁNDEZ RAMOS, Felipe, en “Ecce Homo”, Diccionario de Jesús de Nazaret, Burgos, 2001, pág. 301.

${ }^{13}$ Sobre estos aspectos véase: FERNANDEZ RAMOS, Felipe: La realidad suprema y su teofanía definitiva, Universidad Pontificia de Salamanca, Salamanca, 2007, págs. 13-14.
} 
de Juni, en su "Ecce Homo" para la iglesia de Villanueva de Duero, cuyo modelo entronca con esculturas de la antigüedad greco-romana, recordando la grandeza y fuerza de muchos de los bustos de los emperadores romanos. En el siglo XVII será Gregorio Fernández quien plasmaría esta versión en busto (ermita de San José de Azcoitia), como en cuerpo entero (Museo de la Catedral de Valladolid), cuya imagen posee un estudio anatómico, en la que, como se ha dicho, "el recuerdo del Doríforo es evidente"14. El esquema trasmitido por Fernández, inspirado en una composición grabada del Bautismo de Cristo de Cornelis Cort ${ }^{15}$, tuvo su repercusión en la geografía castellana y leonesa.

Pero será en tierras andaluzas, y más concretamente en Granada, donde el busto del "Ecce Homo" más y mejor se prodigó, bien con esquema de algo más de media figura, cortado por debajo de la cintura, o corto, solamente la cabeza con el cuello y parte de hombros y pecho. En este género escultórico se especializaron un buen número de escultores andaluces quienes algunos de ellos lograron las más altas cotas estéticas en este tipo de manifestaciones, superando con mucho a otros focos escultóricos españoles que también realizaron este tipo iconográfico ${ }^{16}$.

No pretendemos hacer una enumeración total de los escultores andaluces que nos legaron este tipo de manifestaciones, ni por supuesto enumerar las largas listas de las mismas, pues en modo alguno puede ser este el espacio para ello, por eso haremos una breve relación. Los primeros artífices mas destacados en este tipo de iconografías fueron los hermanos García de quienes hay obras desde las últimas décadas del siglo XVI hasta las primeras del siguiente. A continuación, viene Alonso de Mena, pero fundamentalmente será su hijo Pedro quien va a elevar esta modalidad, amplia en su producción, a la más alta gradación estética, si bien en este caso la imagen de Jesús generalmente entrará en combinación con la de la Virgen Dolorosa. La visión de Jesús la dejó maravillosamente recogida bien en solo busto o en busto alargado hasta un poco por debajo de la cintura con los brazos cruzados o sobrepuesto y con gestos de dolor concentrado. Respondiendo a la tipología de busto alargado con unos modelos humanos exquisitamente modelados se hallan, entre otros, las dos muestras magistrales del convento de las Descalzas Reales o el del Museo Nacional de Artes Decorativas, ambas en Madrid. Pero, estos esquemas cristíferos de Pedro no murieron con él, pues una no despreciable nómina de escultores siguieron imitando, con mejor o peor suerte, estos preciados iconos, destacando entre tantos, por su singular calidad, el firmado por Juan Alonso Vallabrille y Ron en 1726 para el convento de San Quince de Valladolid.

También los Mora, Bernardo y José, probaron fortuna en este género pasio-

\footnotetext{
14 URREA, Jesús: "Catálogo”, Gregorio Fernández, 1576-1636, Madrid, 1999, pág. 134

15 NAVARRETE PRIETO, Benito: "Fuentes y modelos en la obra de Gregorio Fernández", Gregorio Fernández, 1576-1636, op. cit., pág. 56.

16 Sobre el círculo granadino puede consultarse: LÓPEZ-GUADALUPE MUÑOZ, Juan Jesús: "Entre la narración y el símbolo. Iconografía del Ecce Homo en la escultura barroca granadina", Boletín de Arte, $n^{\circ} 29$, Universidad de Málaga, Málaga, 2008, págs. 85-111.
} 
nista. Bernardo, vinculado familiarmente con Pedro de Mena, realizó un ejemplar para la Capilla Real de Granada, pero sería su hijo José quien conseguiría una mayor relevancia en este campo, siendo autor de un buen número de ejemplares, emparejados frecuentemente con la Madre Dolorosa. En estos ofrece generalmente una tipología de busto cortado por debajo de los hombros, resultando entre tanto y bueno el que se halla en el Convento del Corpus Christi de Granada. Al igual que en el caso de Pedro de Mena, también hubo escultores que siguieron los pasos de José de Mora prolongando su estela hasta bien entrado el siglo XVIII, entre otros su hermano Diego, José Risueño o Ruiz del Peral. Cerramos estas singulares manifestaciones barrocas con la extraordinaria aportación de Luisa Roldán. La escultora, en los exponentes de Cádiz, Córdoba y el que ahora estudiamos, tomó como fuente de inspiración un grabado de Durero y de un modo más puntual lo recogió en el que ahora nos ocupa. Estos tres Ecce Homo, de muy alta calidad estética, aportan una nueva frescura a la larga nómina de este género tan del gusto del barroco español. 
